\title{
Poesia e historicidade em Manuel Bandeira
}

\author{
Fábio Augusto Steyer*
}

\begin{abstract}
Resumo
Este texto tem o objetivo de analisar a obra e a biografia de Manuel Bandeira a partir da confluência entre poesia e historicidade, tendo como foco principal uma revisão da postura dicotômica que durante muito tempo norteou a teoria literária. A autobiografia do poeta, "Itinerário de Pasárgada", é o ponto de partida para este texto, que também busca subsídios em autores como Fábio Lucas, Alfredo Bosi, Richard Tarnas e Ribeiro Couto, entre outros.
\end{abstract}

Palavras-chave

Poesia. Historicidade. Manuel Bandeira. Crítica literária.

Muito Antes de Pasárgada a terra estava aqui.

Jaime Vaz Brasil.

Em "Itinerário de Pasárgada", sua autobiografia, Manuel Bandeira nos fornece uma série de pistas para a análise da historicidade de sua obra poética. As informações vão desde a influência de sua infância e de seus pais, passando pela música e outras manifestações artísticas e culminando com a inevitável referência aos problemas de saúde que, de certa forma, geraram poemas de intenso lirismo como Vou-me Embora Pra Pasárgada ou Desencanto.

A apropriação dessas referências biográficas facilmente pode resultar em uma análise historicista da obra de Bandeira, o que sobremaneira se deve evitar, sob o risco de se desconsiderar a importância dos aspectos formais da poesia. Sempre é bom lembrar que a Teoria da Literatura, durante muito tempo, oscilou entre uma análise exageradamente formalista ou radicalmente historicizante, a partir de uma visão de mundo bipolar, oriunda das bases do pensamento moderno (cujas origens mais remotas talvez possam ser encontradas no Renascimento Cultural, a partir do século XIII), em que as dicotomias texto $x$ contexto, poesia $x$ historicidade ou forma $x$ conteúdo pareciam bem claras e definidas, a partir de uma visão racional e objetiva da

\footnotetext{
* Professor de Literatura Brasileira no Departamento de Letras Vernáculas da Universidade Estadual de Ponta Grossa, Paraná. Doutor em Literatura Brasileira (UFRGS). Mestre em História do Brasil (PUCRS).
} 
realidade. O século XX, no entanto, definido por Richard Tarnas, em seu livro "A Epopéia do Pensamento Ocidental", como o século da "crise da linguagem" (1999, p. 424-426), mostrou à Filosofia e, consequentemente, a todas as áreas de conhecimento que se pretendam científicas, como é o caso da Teoria da Literatura, que esta visão dicotômica de mundo não funciona, que há um entrelaçamento entre os pólos aparentemente opostos, como é o caso de realidade e ficção, texto e contexto, enfim, poesia e historicidade. Trata-se de admitir a falta de equivalência entre linguagem e realidade, o que no caso da Teoria da Literatura significa aceitar a interpenetração entre texto e contexto para que se possa extrair deste "híbrido" alguma espécie de sentido; não o formalismo puro e simples, que renega totalmente as possibilidades da linguagem em atingir ao menos alguns aspectos da realidade, sendo ela, linguagem, fator determinante da própria realidade (lembremos de Wittgenstein, para quem a linguagem é uma "gaiola", que nos aproxima e ao mesmo tempo nos afasta da realidade ela mesma), e nem o historicismo ingênuo de certos modelos da modernidade, a partir dos quais se acreditava na equivalência total entre linguagem e realidade. (TARNAS, 1999, p. 426).

Alfredo Bosi, no prefácio de "O Ser e o Tempo da Poesia", defende uma idéia plural acerca das relações entre a poesia e a sua historicidade, entre a forma e o conteúdo, o texto e o contexto, enfim, o ser e o tempo da poesia. Portanto, para Bosi não basta considerar separadamente os aspectos internos (formais) ou externos (históricos) da poesia. É preciso, isto sim, justapor esta dualidade, reconhecer que suas relações são múltiplas, plurais, e que ambas não existem isoladamente.

Diz Alfredo Bosi (1997, p. 13-14):

\begin{abstract}
Contextualizar o poema não é simplesmente datá-lo: é inserir as suas imagens e pensamentos em uma trama já em si mesma multidimensional; uma trama em que o eu lírico vive ora experiências novas, ora lembranças de infância, ora valores tradicionais, ora anseios de mudança [...]. A poesia pertence à História Geral, mas é preciso conhecer qual é a história peculiar imanente e operante em cada poema.

[...]

Só uma concepção renovada de historicidade da prática simbólica pode dar conta das imbricações de sujeito e trama social, mesmo porque o que chamamos genericamente de 'sociedade' entra no sujeito na medida em que o sujeito se forma e se transforma no drama das relações com outros sujeitos e consigo mesmo.
\end{abstract}

Pensando Manuel Bandeira a partir dos pressupostos de Bosi, não nos interessa neste texto fazer uma análise pura e simplesmente biográfica da obra do poeta, mas, sim, encontrar traços biográficos na sua poesia, buscando quebrar a dicotomia entre ser e tempo, ou melhor, entre poesia e historicidade. É no interstício entre texto e contexto, tênue fio rude, na tensão que equilibra e desequilibra ao mesmo tempo as inúmeras tentativas de análise racional da poesia, que está o emaranhar-se absoluto entre ser e tempo; algo inatingível, talvez, mas de forma alguma impossível de ser almejado e analisado. É a historicidade em sua forma mais plural, no entrelaçamento de "ser" e "poesia".

A maior tentação quando se trata de Manuel Bandeira é afirmar que sua poesia é um simples reflexo de sua vida, especialmente da doença com a qual conviveu 
durante anos e anos de sua existência: a tuberculose. Mas isso seria submeter o ser ao tempo, a poesia à historicidade, resultando exatamente naquilo que não desejamos fazer, ou seja, uma análise puramente biográfica.

Desta forma, pensando na historicidade ou no tempo da poesia como algo múltiplo, plural, em que também deve ser considerada a poesia em si mesma, em sua ontologia, podemos analisar a confluência entre a vida e a obra de Bandeira a partir de determinados pontos de vista que de modo algum se excluem, mas se complementam e se interpenetram.

Uma primeira possibilidade de análise seria considerar aqueles poemas em que a temática é a própria vida de Manuel Bandeira. Sob este viés podemos encontrar uma série de traços biográficos do poeta como referência direta nos próprios poemas. Como exemplos, podemos citar aqueles poemas que tematizam a doença de Bandeira e um certo desencanto com a existência, como é o caso de Testamento, Desencanto e Voume Embora Pra Pasárgada. De acordo com o próprio Bandeira, em sua autobiografia, a ideia de um mundo diferente, em que a realidade seria mais bela e tranquila, quase que uma Callipolis moderna, teve origem em sua infância, a partir da leitura de Viagem à Roda do Mundo Numa Casquinha de Noz. (BANDEIRA, 1954, p. 11). Mais tarde, a referência à palavra "Pasárgada", o "campo dos persas" que nada mais é do que a cidade fundada pelo conquistador Ciro no mundo antigo, fez amadurecer a utopia de Bandeira, que diz ver no poema "toda a sua vida", com toda a intensidade de suas alegrias e tristezas: "Não sou arquiteto, como meu pai desejava, não fiz nenhuma casa, mas reconstruí, e não como 'uma forma imperfeita neste mundo de aparências', uma cidade ilustre, que hoje não é mais a Pasárgada de Ciro, e sim a 'minha' Pasárgada" (BANDEIRA, 1954, p. 93-94). Como em Consoada, com "a casa limpa/a mesa posta/com cada coisa em seu lugar" ou em Canção do Vento e da Minha Vida, em que a vida ficava "cada vez mais cheia de tudo", Bandeira conseguiu apaziguar suas mágoas e insatisfações através da poesia, fornecendo ainda "à angústia de muitos uma palavra fraterna" (BANDEIRA, 1954, p. 131). Essa confluência de ser e tempo, de poesia e historicidade que se processou com o próprio Bandeira, enquanto ser humano, (e com seus leitores, num processo em que a poesia serve de catarse para a dura realidade), por si só já nos demonstra a inseparabilidade entre forma e conteúdo e, no limite, entre arte e realidade, mesmo que ainda tenhamos como centro uma abordagem biográfica de sua obra poética.

\section{Primeiro texto $^{1}$}

Fácil seria provar quanto a tuberculose explica a poesia de Manuel Bandeira; mas não apenas a tuberculose como enfermidade e sim como conjunto de condições de vida a que ela o obrigou. As suas variações de tema e de processos, que puderam servir de base a um libelo acusatório, representam as forçosas variações de saúde e de atmosfera psicológica. São a carte routière de suas peregrinações físicas e morais. Pela sensibilidade, no corpo prisioneiro, o poeta tomava parte no espetáculo proibido. Os jogos de arte, aparentemente diletantes, eram a medida de relação entre o seu drama pessoal e a impossível existência ativa. $O$ célebre verso

\footnotetext{
${ }^{1}$ Os textos inseridos neste trabalho visam complementar a análise do corpo principal do estudo a partir da inclusão de informações e referências adicionais, em especial afirmações do próprio Manuel Bandeira e de outros importantes intelectuais sobre sua vida e obra.
} 
'Eu faço versos como quem morre' não era Literatura. Durante muitos anos cada dia foi para ele a véspera do último. Cada poema era uma despedida. Território parnasiano, simbolista, clássico, romântico, etc., que importavam as etiquetas? As fronteiras entre os diversos territórios temáticos e processuais não o interessavam: ele viajava perto das nuvens. O importante, aliás, para todo aquele que vive a aventura da viagem artística, é chegar um dia a regiões desconhecidas e poder dar o seu nome a um território próprio. Ele chegou a esse território: descobriu a ilha de Pasárgada.

Ribeiro Couto, em "De Menino Doente a Rei de Pasárgada".

Seguindo esta primeira linha de raciocínio, também podemos abordar aqueles poemas em que aparecem traços da infância de Manuel Bandeira, como é o caso de Evocação do Recife e Infância. Em ambos a referência a sua biografia é explícita, sendo feita inclusive em primeira pessoa. Sobre a variação de formas "Capiberibe" e "Capibaribe", em Evocação do Recife, o próprio Bandeira afirma que é uma alusão direta a uma discussão que teve com José Veríssimo, seu professor de Geografia no Colégio Pedro II, sobre qual seria a forma correta. Veríssimo tirou sarro de Bandeira por este ser pernambucano e pronunciar erroneamente "Capiberibe" (BANDEIRA, 1954, p. 45). A "desforra" só veio com o poema: não está aí uma prova cabal de que mesmo numa análise que privilegia a biografia do poeta temos uma confluência entre poesia e historicidade? A "vingança" de Bandeira veio através da arte, num poema que formalmente ultrapassa o nível da referência direta ao episódio com José Veríssimo, adquirindo vida própria e uma multiplicidade de significados, mas contemplando o processo de catarse que envolve a realidade vivida do poeta.

\section{Segundo texto}

O caso do poema 'Recife' [...] é ainda uma prova da extrema modéstia de Manuel Bandeira. A gente poderá, não tem dúvida, lendo o título e o início do poema, imaginar que o poeta vai cantar as grandezas e belezas de sua terra natal, mas logo se desilude porém. O poeta logo converte o seu assunto ao poeta, não às características exteriores e adquiridas do poeta, não ao seu processo de versejar, ao seu estilo, a tiradas nem metáforas, mas à sua naturalidade mais intrínseca, mais incontestável, suas recordações de sua vida vivida, saudades de infância. Modestamente, Recife é a vida que o poeta viveu menino em um vilarejo qualquer, um engenho, uma fazenda. Não é mais um assunto nacional, é um assunto do poeta vivendo no seu cantinho.

[...]

E por isso talvez, ou pelo menos em grande parte por isso, ele me parece o maior dentre nós, porque o mais idêntico a si mesmo.

Mário de Andrade, em "Da Modesta Grandeza".

Este episódio com José Veríssimo revela uma nova possibilidade de análise da obra poética de Bandeira: a presença de aspectos biográficos não como mera temática dos poemas, mas adquirindo outros sentidos, numa confluência um pouco mais sofisticada da poesia e sua historicidade, da forma com o conteúdo, enfim, do ser e do tempo da poesia. 
Outros exemplos disso são as referências que o poeta faz a seus pais. É através do "Itinerário de Pasárgada" e do discurso proferido por Ribeiro Couto quando do ingresso de Bandeira na Academia Brasileira de Letras que ficamos sabendo de algumas informações a respeito. Alguns versos de Trem de Ferro ("Quando me prendero/No canaviá/Cada pé de cana/Era um oficiá.") são uma referência indireta à retórica do pai de Bandeira, engenheiro Manuel Carneiro de Sousa Bandeira, grande contador de histórias populares e folclóricas do norte do País. Os versos citados, embora assumam outras possibilidades de significado no poema (e aí está a sofisticação da confluência entre poesia e historicidade), aludem a uma história contada a Bandeira, quando criança, pelo pai, sobre o medo de um negro fugitivo, para quem "cada pé de cana era um oficiá." (COUTO, 1960, p. 52).

Também do pai vêm alguns versos de Testamento ("Tive uns dinheiros - perdios.../Tive amores - esqueci-os."). Eles provêm de um diálogo do pai de Bandeira com um pedinte, ocasião em que este recitou um poema que incluía os seguintes dizeres na última estrofe: "Tinha uns chinelos... Vendi-os/Tinha uns amores... Deixei-os." (COUTO, 1960, p. 52-53). Mais uma vez temos um episódio da biografia de Bandeira, de seu contato com o pai, que foi lançado em sua poesia não como episódio em si, mas assumindo a dimensão plural da historicidade, em que arte e realidade, texto e contexto se confundem, resultando em múltiplos significados e interpretações que transcendem o fato "histórico" ou "biográfico" em si, entrelaçando-se poesia e historicidade. O mesmo acontece quando Bandeira, em Contrição, utiliza o termo "Meu Deus valei-me", que tantas vezes ouviu da boca de sua mãe. (COUTO, 1960).

\section{Terceiro texto}

O meu primeiro contacto com a poesia sob a forma de versos terá sido provavelmente em contos de fadas, em histórias da carochinha. No Recife, depois dos seis anos.

$[\ldots]$

Aos versos dos contos da carochinha devo juntar os das cantigas de roda, algumas das quais sempre me encantaram, como 'Roseira, dá-me uma rosa', 'O anel que tu me deste', 'Bão balalão, senhor capitão', 'Mas pra que tanto sofrimento'. Falo destas porque as utilizei em poemas. E também as trovas populares, coplas de zarzuelas, couplets de operetas francesas, enfim, versos de toda a sorte que me ensinava meu pai.

Manuel Bandeira, em "Itinerário de Pasárgada"

Uma terceira possibilidade de analisar a presença da historicidade na obra poética de Bandeira, talvez a mais sofisticada de todas, a que mais se afasta de um estudo biográfico, seria buscar traços de sua vida nos aspectos formais de seus poemas. Nesse sentido, o "Itinerário de Pasárgada" também nos fornece diversas pistas, como é o caso da intensa paixão que Bandeira nutria pela música. Na Evocação do Recife, por exemplo, a utilização dos termos "Capiberibe" e "Capibaribe", além de ser explicada pelo episódio com José Veríssimo, comentado anteriormente, possui, de acordo com Bandeira, uma intenção musical: "Capiberibe a primeira vez com e, a segunda com a, me dava a impressão de um acidente, como se a palavra fosse uma 
frase melódica dita da segunda vez com bemol na segunda nota. De igual modo, em 'Neologismo' o verso 'Teadoro, Teodora' leva a mesma intenção" (BANDEIRA, 1954, p. 45). Desta maneira, temos um traço biográfico marcante de Bandeira, sua paixão pela música, que interfere diretamente na "forma" de sua poesia. Aqui parece que poesia e historicidade, ser e tempo, realmente se fundem, e a quebra de uma visão de mundo bipolar e dos radicalismos de certas Teorias da Literatura se concretiza de uma forma mais intensa. O mesmo acontece quando Bandeira atribui a repetição de um ou mais versos em vários de seus poemas (Cartas de meu avô, Poemeto Irônico, Vulgívaga, 0 Inútil Luar, entre outros) à música, e não a determinados modelos literários (BANDEIRA, 1954, p. 44). Não se deve esquecer que Bandeira teve diversos poemas musicados (por compositores do porte de Villa-Lobos, Radamés Gnatalli e Tom Jobim, entre outros), além de também ter escrito letras para melodias já compostas anteriormente.

\section{Quarto texto}

Maior ainda foi em mim a influência da música. Na verdade, faço versos porque não sei fazer música. Não há nada no mundo de que eu goste mais do que de música. Sinto que na música é que conseguiria me exprimir completamente.

[...]

Assim como certos poemas admitem pluralidade de sentido ou de interpretações, como que em qualquer texto literário há infinito número de melodias implícitas.

Manuel Bandeira, em "Itinerário de Pasárgada".

Um belo exemplo da musicalidade dos versos de Manuel Bandeira é Trem de Ferro, em que o ritmo do poema lembra o movimento do próprio trem, incorporando passagens de sua biografia (como o caso de "Quando me prendero/No canaviá/Cada pé de cana/Era um oficiá") que assumem novos significados formais e temáticos. O "trem de verso" de Bandeira ("Oô...") dá ritmo ao poema e "conduz" musicalmente as estrofes: "Foge, bicho/Foge, povo/Passa ponte/Passa poste/Passa pasto/Passa boi/Passa boiada [...]."

A repetição das palavras ou frases reforça o aspecto rítmico e melódico do poema ("Café com pão/Café com pão/Café com pão"), pois esse verdadeiro "comboio poético" não pode parar: "Vou depressa/Vou correndo/Vou na toda/Que só levo/Pouca gente/Pouca gente/Pouca gente...." Em Trem de Ferro nota-se o quanto a presença da música na vida de Bandeira foi importante para a construção de sua obra poética, sendo um exemplo muito esclarecedor da confluência entre poesia e historicidade que até aqui temos analisado. A musicalidade de Trem de Ferro fica mais evidente ainda no momento em que ficamos sabendo ter sido este poema musicado diversas vezes, sendo talvez a versão mais interessante e bem realizada a de Tom Jobim, que, além de explorar de uma forma perfeita os aspectos rítmicos e melódicos dos versos em si, acrescentou à obra mais intensidade musical a partir da própria melodia e do trabalho vocal com os integrantes da Família Jobim. 
O crítico literário Fábio Lucas aponta outra questão importante com relação à influência da música sobre os aspectos formais da obra poética de Bandeira. De acordo com o autor, quando Manuel Bandeira se qualifica de "poeta menor", não estaria ele afirmando que é inferior ou menos importante do que outros poetas, mas assumindo, na interpenetração do ser e do tempo de sua poesia, uma enorme influência de traços de sua historicidade sobre sua obra poética. Para Lucas (1987, p. 5),

\begin{abstract}
Manuel Bandeira [...] estaria adotando uma visão musical de classificação, indicando o tom - 'menor' - em que são compostos os seus poemas, diferentemente de outros poetas, que procuram afinar-se pelo 'tom maior'. Tal distinção torna mais compreensiva a distribuição dos poetas entre 'maiores' e 'menores', desprezando-se, portanto, o dimensionamento por ordem de grandeza, quando se sabe da impalpável magnitude da realidade poética.
\end{abstract}

E o crítico vai mais longe ainda, associando a própria natureza da poesia à musicalidade, lembrando os aspectos fonéticos de nossa modalidade de escrita (LUCAS, 1987):

\begin{abstract}
Ademais, todo signo impresso, toda letra, constitui um som virtual, pois se trata da fixação do som na escrita. A letra, portanto, equivale a uma notação musical. Um bom leitor de música não carece do instrumento para ouvir a partitura, assim o bom leitor de poesia pode avaliar o tom - maior ou menor - da composição.
\end{abstract}

Esse "tom menor", para Fábio Lucas, também estaria intimamente ligado a questões de natureza temática: "Bandeira dificilmente sai do campo de suas dores e de seu mundo interior, a colher impressões sombrias ou faceiras da hora que passa." (LUCAS, 1987). Nesse sentido, o "tom menor" de seus poemas seria uma espécie de representação do "tom menor" de sua própria vida. Parece-nos que a partir desta visão a confluência entre forma e conteúdo, texto e contexto, poesia e historicidade atinge um alto grau de complexidade, sempre tendo a influência da música sobre a vida de Bandeira como centro da análise.

\title{
Quinto texto
}

Tomei consciência de que era um poeta menor: que me estaria para sempre fechado o mundo das grandes abstrações generosas; que não havia em mim aquela espécie de cadinho onde, pelo calor do sentimento, as emoções morais se transmudam em emoções estéticas: o metal precioso eu teria que sacá-lo a duras penas, ou melhor, a duras esperas, do pobre minério das minhas pequenas dores e ainda menores alegrias.

Manuel Bandeira, em "Itinerário de Pasárgada"

Criou-me, desde eu menino,

Para arquiteto meu pai.

Foi-se-me um dia a saúde...

Fiz-me arquiteto? Não pude!

Sou poeta menor, perdoai!

"Testamento" 
A presença da historicidade na obra de Manuel Bandeira, tal como foi tratada até aqui, numa tentativa de se encontrar algumas possibilidades de interpretação na múltipla e plural correlação entre o "ser e o tempo da poesia", também encontra respaldo nas ideias do filósofo italiano Luigi Pareyson, para quem a obra de arte (no caso, a poesia) e a sua historicidade não devem ser analisadas separadamente, a partir de estudos excessivamente formalistas ou, ao contrário, radicalmente biográficos ou historicizantes.

De acordo com Pareyson (1989, p. 130-135),

\begin{abstract}
O modo de conceber a historicidade da arte não é sempre tal, que comprometa sua especificação, e que afirmar a especificação da arte não significa, necessariamente, negar sua historicidade

[...]

É necessário um ulterior aprofundamento das relações da arte com a história. Estas relações são duplas, porque, por um lado, dizem respeito a sua emergência da história e, por outro, à sua presença nela; de uma parte, à sua intemporalidade e, de outra, à sua temporalidade.

[...]

A gênese da obra, temporal no seu ato, é intemporal no seu efeito: a obra, mesmo sendo filha de seu tempo, dele emerge e, de certo modo, dele sai para mover-se no espaço com a universalidade e perenidade de seu valor, em qualquer tempo, para além de qualquer circunstância histórica.
\end{abstract}

Pareyson, portanto, defende uma visão equilibrada das relações entre poesia e historicidade, o que nos parece algo ainda muito distante da realidade de grande parte (não toda, felizmente) da crítica literária contemporânea, ainda presa a uma visão científica e epistemológica que privilegia análises dicotômicas e maniqueístas da realidade. Como já foi dito certa vez em um poema, parece que no mundo contemporâneo cada vez fica mais claro que "O dualismo/Unifica falsas verdades opostas." (Poema sem título, STEYER, 2003, p. 25).

Concluindo, gostaríamos ainda de fazer referência a outro conceito de Alfredo Bosi que entendemos ser bastante adequado à vida e à obra de Manuel Bandeira: trata-se do conceito de "poesia resistência". Amplamente discutida no seu livro "Literatura e Resistência" e também em "O Ser e o Tempo da Poesia", a ideia da poesia como resistência não diz respeito apenas a questões políticas ou ideológicas, como pode parecer num primeiro nível de análise. A "resistência" pode se manifestar de diversas maneiras, não se restringindo de forma alguma ao conteúdo, à temática, enfim, ao "tempo" da poesia. Ela pode também ser existencial, como no caso de Bandeira, pois o poeta "resiste" às agruras de sua própria vida através da poesia. Além disso, na confluência entre a poesia e sua historicidade, a resistência pode ser quanto aos aspectos formais da obra (o "ser" da poesia), o que igualmente pode ser relacionado com Manuel Bandeira, um dos primeiros autores brasileiros a se libertar das convenções formais e acadêmicas da obra poética.

Segundo Fábio Lucas (1989, p. 7), 
Ele [Bandeira] trouxe para a poesia nacional os primeiros momentos de uma certa liberdade formal e vocabular, rompendo velhos tabus linguísticos e preconceitos verbais. Daí o emprego de uma elocução direta, sem rodeios, na invocação dos apelos eróticos, certa rudeza lexical que chegou a chocar nos primeiros momentos, pois tudo passou a ser dito sem polidez, abrandamentos ou eufemismos.

Encurtava-se a distância entre o registro de situações formais e informais de comunicação, de tal sorte que as regras de defesa do decoro literário se foram revogando.

A "poesia resistência", portanto, assume uma multiplicidade de formas, que vão da poesia à historicidade, do texto a seu contexto, da forma ao seu conteúdo, dualidades que no mundo contemporâneo cada vez mais precisam ser vistas de forma integrada, sem o maniqueísmo dos opostos; a justaposição destes pólos antagônicos, parece-nos, é que nos permite uma visão mais equilibrada da realidade. No caso em questão, foi nosso objetivo apresentar algumas possibilidades de análise da historicidade na obra de Manuel Bandeira a partir desta visão. Historicidade esta que se manifesta no texto e no contexto, na forma e no conteúdo, e que deve, portanto, compreender, em igual medida, a análise do "ser" e do "tempo" da poesia, rompendo com os exageros do formalismo e do historicismo. Ambos são válidos, mas apenas quando pensados de forma integrada, com suas múltiplas possibilidades de interpretação. O próprio Manuel Bandeira já dizia: "Jamais fiz um poema ou verso ininteligível para me fingir de profundo sob especiosa capa de hermetismo. Só não fui claro quando não pude - fosse por deficiência ou impropriedade de linguagem, fosse por discrição." (BANDEIRA, 1954, p. 95).

Cabe a nós, a partir da confluência do "formal" com o "histórico", interpretar os sentidos plurais ocultos na obra poética de Bandeira. Talvez então percebamos que mesmo com a chamada "crise da linguagem" do século XX, apontada por Wittgenstein e desencadeada pelo estruturalismo advindo de Ferdinand de Saussure, existe algo muito maior do que as palavras... (TARNAS, 1999, p. 426)

Afinal, como disse o poeta Jaime Vaz Brasil, "muito antes de Pasárgada/A Terra estava aqui". Nós, humanos, estamos aqui. E Manuel Bandeira, mesmo após a morte, continua vivo em sua obra poética.

Ele varreu seus medos, seus traumas, suas angústias, preenchendo os vazios de sua própria biografia através da poesia. Hoje sua poesia e historicidade preenchem os vazios dos leitores, deixando suas vidas "cada vez mais cheias de tudo", como se a poesia dissesse "as coisas mais simples e menos intencionais", fosse "ardente como um soluço sem lágrimas", tivesse "a beleza das flores quase sem perfume", "a pureza da chama em que se consomem os diamantes mais límpidos" ou "a paixão dos suicidas que se matam sem explicação."

\section{Referências}

BANDEIRA, Manuel. Itinerário de Pasárgada. São Paulo: Jornal de Letras, 1954.

Libertinagem/Estrela da Manhã. Rio de Janeiro: Nova Fronteira, 2000. 
. Melhores poemas. Seleção de Francisco de Assis Barbosa. São Paulo:

Global, 2001.

BOSI, Alfredo. Literatura e resistência. São Paulo: Companhia das Letras, 2002. . O ser e o tempo da poesia. São Paulo: Cultrix, 1997.

BROOKER, Peter, SELDEN, Raman e WIDDOWSON, Peter. La teoría literaria contemporánea. Barcelona: Ariel, 2001.

COUTO, Ribeiro. Dois retratos de Manuel Bandeira. Rio de Janeiro: São José, 1960. LOPEZ, Telê Porto Ancona (Org.). Manuel Bandeira - Verso e Reverso. São Paulo: T. Queiroz, 1987.

PAREYSON, Luigi. Os problemas da estética. São Paulo: Martins Fontes, 1989.

STEYER, Fábio Augusto. Ser disperso. Porto Alegre: WS Editor, 2003.

TARNAS, Richard. A epopéia do pensamento ocidental. Rio de Janeiro: Bertrand Brasil, 1989.

\section{Title}

Poetry and history in Manuel Bandeira

\section{Abstract}

This paper aims to examine the work and the biography of Manuel from the confluence between poetry and history, focusing mainly on a review of the dichotomous approach that has long guided the literary theory. The autobiography of the poet, "Itinerário de Pasárgada," is the starting point for this text, which also seeks grants authors as Fabio Lucas, Alfredo Bosi, Richard Tarnas and Couto, among others.

\section{Keywords}

Poetry. Historicity. Manuel Bandeira. Literary criticism.

Recebido em 05/10/2012. Aprovado em 20/11/2012. 